\title{
Multiple epiphyseal dysplasia type 5
}

INSERM

\section{Source}

INSERM. (1999). Orphanet: an online rare disease and orphan drug data base. Multiple epiphyseal dysplasia type 5. ORPHA:93311

Multiple epiphyseal dysplasia type 5 is a multiple epiphyseal dysplasia characterized by an early-onset of pain and stiffness (involving knee and hip), progressive deformity of the extremities and precocious osteoarthritis associated with delayed and irregular ossification of epiphyses. Features specific to multiple epiphyseal dysplasia, type 5 include normal stature and lesser incidence of gait abnormalities. Radiographs reveal epiphyseal and metaphyseal irregularities. Multiple epiphyseal dysplasia type 5 follows an autosomal dominant mode of transmission. 